\title{
Relationship between the extent of dissection and platelet activation in acute aortic dissection
}

\author{
Shu Zhang ${ }^{1 \dagger}$, Hong Qian ${ }^{2 \dagger}$, Qin Yang ${ }^{3}$, Jia Hu${ }^{2}$, Changping Gan ${ }^{2}$ and Wei Meng ${ }^{2 *}$
}

\begin{abstract}
Background: The extent of acute aortic dissection (AAD) was correlated with inflammation positively. On the other side, inflammation was negatively correlated with mean platelet volume (MPV), which can reflect platelet (PLT) activation. The aim of this study was to clarify the relationship between the extent of dissection and PLT activation.

Methods: Between February 2010 and October 2013, 147 patients with acute aortic dissection (AAD) were divided into Group 1 (Stanford A, $n=59$ ) and Group 2 (Stanford B, $n=88$ ). Platelet count, MPV and platelet size distribution width (PDW) were measured to assess PLT activation. Additionally, the severity of inflammation was assessed via serum C-reactive protein (CRP), white blood cell (WBC) count and the neutrophil percent (Neut\%). Computerized tomography (CT) was employed to analyze the extent of AAD. Volume tear index (VTI) was calculated as the false lumen (FL) volume divided by body surface area (BSA).
\end{abstract}

Results: PLT count was significantly lower in group 1 than in group $2\left(137.24 \pm 31.04 \times 10^{9} / \mathrm{L}\right.$ vs $171.43 \pm 27.57 \times 10^{9} / \mathrm{L}$, $P<0.001)$. The MPV/PLT ratio and PDW were significantly higher in the group 1 respectively $(0.08 \pm 0.02$ vs $0.06 \pm$ $0.02, P<0.001 ; 22.65 \pm 1.87 \mathrm{fl}$ vs $20.69 \pm 1.97 \mathrm{fl}, P<0.001)$. The CRP was significantly higher in group 1 than in group $2(36.40 \pm 8.89 \mathrm{mg} / \mathrm{L}$ vs $28.97 \pm 8.48 \mathrm{mg} / \mathrm{L}, P<0.001)$. VTI was significantly higher in group 1 than in group $2(250.12 \pm 27.82$ vs $198.79 \pm 24.52, P<0.001)$. There was a significant negative correlation between $\mathrm{VTI}$ and PLT count $(r=-0.673, P<0.001)$, CRP and PLT count $(r=-0.640, P<0.001)$, respectively. There was a significant positive correlation between VTI and CRP $(r=0.670, P<0.001)$, VTI and PDW $(r=0.601, P<0.001)$, respectively.

Conclusions: PLT activation and inflammation in AAD appear to be closely correlated with the extent of dissection, which possibly induced by the tear of aortic wall. Elimination of the false lumen is the goal of traditional surgery. Suppression of the PLT activation might be future targets of therapy in the prevention of systemic inflammation in AAD patients.

Keyword: Acute aortic dissection, Inflammation, Platelet, Platelet activation, C-reactive protein

\section{Background}

Mean platelet volume (MPV) and platelet size distribution width (PDW) are markers of platelet (PLT) size and variability, which can reflect PLT activation [1-3]. High grade inflammation is associated with low MPV whereas low grade inflammation is associated with high MPV; inflammation may play a role in pathogenesis of aneurysm formation and rupture [3]. Acute aortic

\footnotetext{
*Correspondence: meng_wei_1111@yahoo.com

${ }^{\dagger}$ Equal contributors

${ }^{2}$ Department of Cardiovascular Surgery, West China Hospital of Sichuan

University, Chengdu, China

Full list of author information is available at the end of the article
}

dissection (AAD) is frequently accompanied by systemic inflammatory reaction, which is provoked by acute aortic injury and is reflected in an increment in serum C-reactive protein (CRP), white blood cell (WBC) count and pro-inflammatory cytokine levels [1-4]. In 2010, Manabu [5] reported extent of AAD was correlated with inflammation positively. We hypothesized that extent of AAD might correlate with the PLT activation. To our knowledge, these relationships have never been studied.

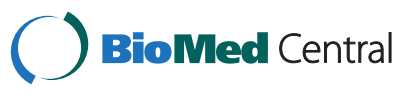

(C) 2015 zhang et al. Open Access This article is distributed under the terms of the Creative Commons Attribution 4.0 International License (http://creativecommons.org/licenses/by/4.0/), which permits unrestricted use, distribution, and reproduction in any medium, provided you give appropriate credit to the original author(s) and the source, provide a link to the Creative Commons license, and indicate if changes were made. The Creative Commons Public Domain Dedication waiver (http://creativecommons.org/publicdomain/zero/1.0/) applies to the data made available in this article, unless otherwise stated. 


\section{Methods \\ Patients}

From February, 2010 to October, 2013. 341 consecutive AAD patients were admitted to the West China Hospital. The following categories of patients $(n=194$ total) were excluded from our study, namely, those presenting later than $48 \mathrm{~h}$ from onset $(n=131)$, those with severe valve dysfunction $(n=27)$, those with recurrent $\operatorname{AAD}(n=15)$, and those with malignant tumor or renal failure $(n=21)$. The remaining $147 \mathrm{AAD}$ patients were enrolled in this study and examined prospectively. The patients were divided into 2 groups according to Stanford classification: Group 1 (Stanford A, $n=59$ ) and Group 2 (Stanford B, $n=88$ ). Blood samples were collected and axillary temperatures were recorded on the time of admission. Platelet count, PMV and PDW were measured to assess PLT activation. Serum CRP levels, WBC count and neutrophil percent (Neut\%) were measured to assess the severity of inflammation. The study was approved by the medical ethics committee of West China Hospital. And all patients joined this study with informed consents.

\section{Analysis for extent of AAD}

In each patient, contrast-enhanced helical CT was performed on a 64-row multidetector scanner (Brilliance 64, Philips Medical Systems, Cleveland, Ohio). Scans were obtained using 120 to $160 \mathrm{~mL}$ of a nonionic contrast agent continuously injected into the right antecubital vein at an infusion rate of $4 \mathrm{ml} / \mathrm{s}$. To ensure maximum contrast intensity in the aorta, the region of interest (ROI) (threshold of 150 Hounsfield units) to trigger the beginning of the scan was placed in the ascending aorta. A second late arterial phase scan was performed, after a delay of 180 to $300 \mathrm{~s}$ from the end of the contrast scan, covering the same area [6]. The data obtained from CT scans were transferred to an Apple MacPro Quad 2.6 Ghz (Apple Corp, Cupertino, Calif) using digital imaging and communications in medicine (DICOM) data sets. The CT scans were stored and analyzed using the OsiriX software (Version 5.8.1 64-bit, Pixmeo SARL, Bernex, Switzerland).

Volumes were analyzed for the entire aorta from the innominate artery to the iliac bifurcation. The areas of interest, needed to calculate volumes, were drawn on CT scan manually (Fig. 1a and b, one selection every three scans),

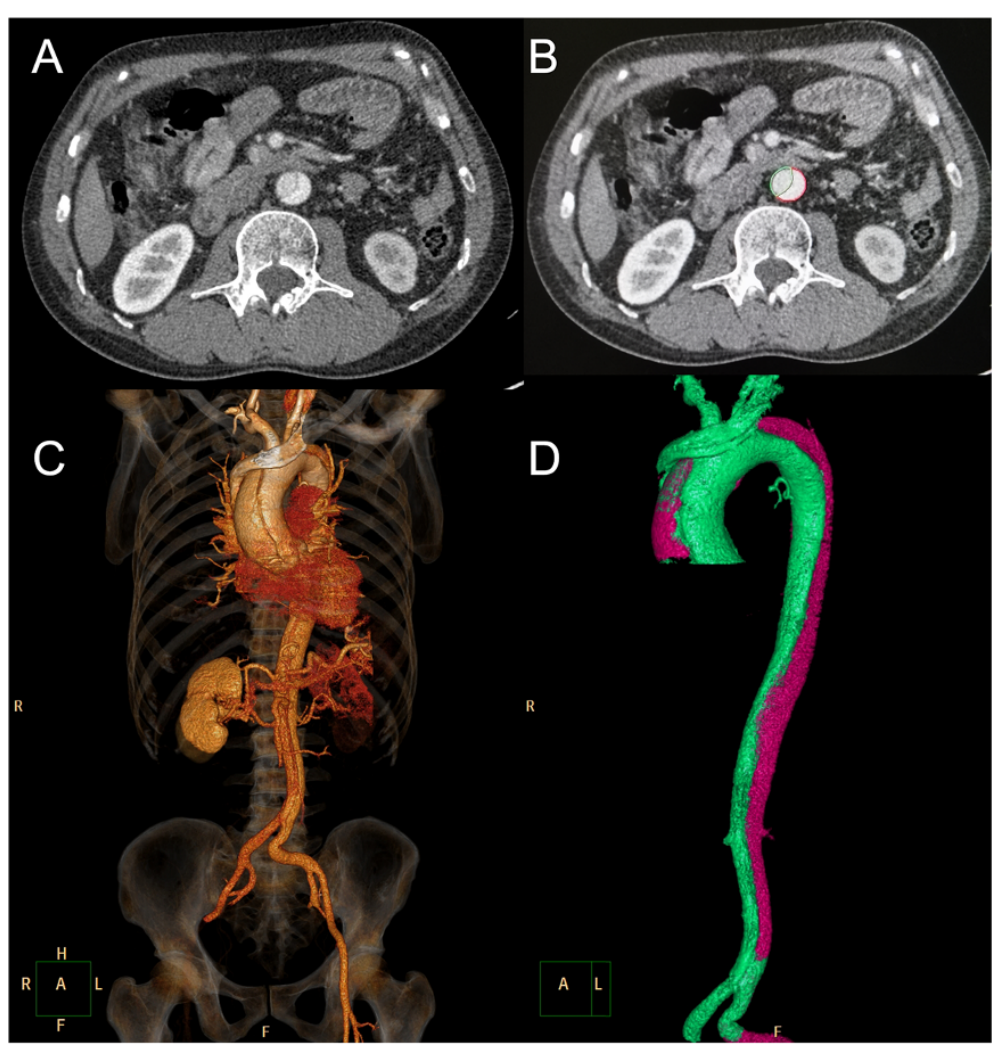

Fig. 1 In each patient, we performed volumetric analysis of contrast-enhanced helical computed tomography (CT) covering the entire aorta starting from the innominate artery to the iliac bifurcation. Segmentations of the true lumen (TL, green) and false lumen (FL, red) were performed and volumes were calculated separately 
and the software provided automatically generating missing areas for every slice (Fig. 1c).

Additionally, the software allowed to perform automated segmentation (determining boundaries around a class of similar voxel intensity), which was used when appropriate and manually adjusted if necessary. The true lumen (TL) and false lumen (FL) volumes were calculated separately, and the overall volumes were calculated using the summation technique (Fig. 1d). Volumes computed by the software were expressed in $\mathrm{cm}^{3}$. For all patients, a volume tear index (VTI) was calculated as the FL volume divided by body surface area (BSA).

\section{Statistical analysis}

Quantitative variables are presented as mean standard deviation and categorical variables as percentages. Continuous variables were compared using the Student's $t$-test, Welch's $t$-test or the Mann-Whitney $U$-test. Categorical data were compared using chi-square tests. Correlations between PLT activation, extent of AAD and inflammation parameters were analyzed by Pearson's correlation coefficient. A $P$ value $<0.05$ was considered statistically significant. All data analysis was carried out using SPSS version 20.0 (SPSS, Inc, Chicago, IL, USA).

\section{Results}

Table 1 showed the baseline characteristics, PLT indices, extent of dissection and inflammatory parameter. The lowest PLT count recorded in all patients was $84 \times$ $10^{9} / \mathrm{L}$. The highest VTI was 291.52 . The highest CRP was $49.40 \mathrm{mg} / \mathrm{L}$.

\section{Baseline characteristics}

The mean age of all patients was $47.13 \pm 10.94$ years, and the majority of patients were male (76.9\%). Baseline characteristics were comparable between two groups, except that the smoking percentage in group 1 was lower than group $2(45.8 \%$ vs. $63.6 \%, P=0.032)$.

\section{PLT indices}

The average of PLT count across all patients was $157.71 \pm$ $33.44 \times 10^{9} / \mathrm{L}$. PLT count was significantly lower in group

Table 1 Characteristics of the Patients

\begin{tabular}{|c|c|c|c|c|}
\hline & Total & Group 1 & Group 2 & P Value \\
\hline \multicolumn{5}{|l|}{ Baseline characteristics } \\
\hline Age, years & $47.13 \pm 10.94$ & $46.05 \pm 11.40$ & $47.85 \pm 10.63$ & 0.330 \\
\hline Male gender, (\%) & & $48(81.4 \%)$ & 65 (73.9 \%) & 0.291 \\
\hline $\mathrm{BSA}\left(\mathrm{m}^{2}\right)$ & $1.69 \pm 0.07$ & $1.68 \pm 0.07$ & $1.69 \pm 0.06$ & 0.234 \\
\hline Time from onset of symptoms (hours) & $24.29 \pm 10.01$ & $23.97 \pm 9.80$ & $24.51 \pm 10.19$ & 0.747 \\
\hline Hypertension & & $31(52.5 \%)$ & $45(51.1 \%)$ & 0.867 \\
\hline Diabetes & & $18(30.5 \%)$ & 29 (33.0 \%) & 0.755 \\
\hline Dyslipidemia & & $13(22.0 \%)$ & $23(26.1 \%)$ & 0.571 \\
\hline Smoking & & $27(45.8 \%)$ & $56(63.6 \%)$ & 0.032 \\
\hline LVEF & $52.62 \pm 7.56 \%$ & $51.98 \pm 7.55 \%$ & $53.05 \pm 7.59 \%$ & 0.406 \\
\hline \multicolumn{5}{|l|}{ PLT indices } \\
\hline PLT count $\left(\times 10^{9} / L\right)$ & $157.71 \pm 33.44$ & $137.24 \pm 31.04$ & $171.43 \pm 27.57$ & $<0.001$ \\
\hline MPV (fl) & $10.56 \pm 1.87$ & $10.62 \pm 1.90$ & $10.51 \pm 1.87$ & 0.718 \\
\hline MPV/PLT ratio & $0.07 \pm 0.02$ & $0.08 \pm 0.02$ & $0.06 \pm 0.02$ & $<0.001$ \\
\hline PDW (fl) & $21.48 \pm 2.15$ & $22.65 \pm 1.87$ & $20.69 \pm 1.97$ & $<0.001$ \\
\hline \multicolumn{5}{|l|}{ Extent of dissection } \\
\hline $\mathrm{FL}$ volume $\left(\mathrm{cm}^{3}\right)$ & $369.42 \pm 57.12$ & $419.31 \pm 42.90$ & $335.98 \pm 37.81$ & $<0.001$ \\
\hline Volume tear index & $219.39 \pm 36.09$ & $250.12 \pm 27.82$ & $198.79 \pm 24.52$ & $<0.001$ \\
\hline \multicolumn{5}{|l|}{ Inflammation parameters } \\
\hline $\mathrm{CRP}(\mathrm{mg} / \mathrm{L})$ & $31.95 \pm 9.36$ & $36.40 \pm 8.89$ & $28.97 \pm 8.48$ & $<0.001$ \\
\hline WBC count & $13.60 \pm 2.95$ & $14.00 \pm 3.07$ & $13.33 \pm 2.85$ & 0.177 \\
\hline Neut $\%$ & $80.84 \pm 5.18$ & $81.83 \pm 5.37$ & $80.17 \pm 4.96$ & 0.056 \\
\hline Axillary temperature $\left(C^{\circ}\right)$ & $37.79 \pm 0.59$ & $37.89 \pm 0.60$ & $37.72 \pm 0.58$ & 0.072 \\
\hline
\end{tabular}

BSA body surface area, LVEF left ventricle ejection fraction, FL false lumen, VTI volume tear index, CRP C-reactive protein, WBC white blood cell, Neut\% neutrophil percent 

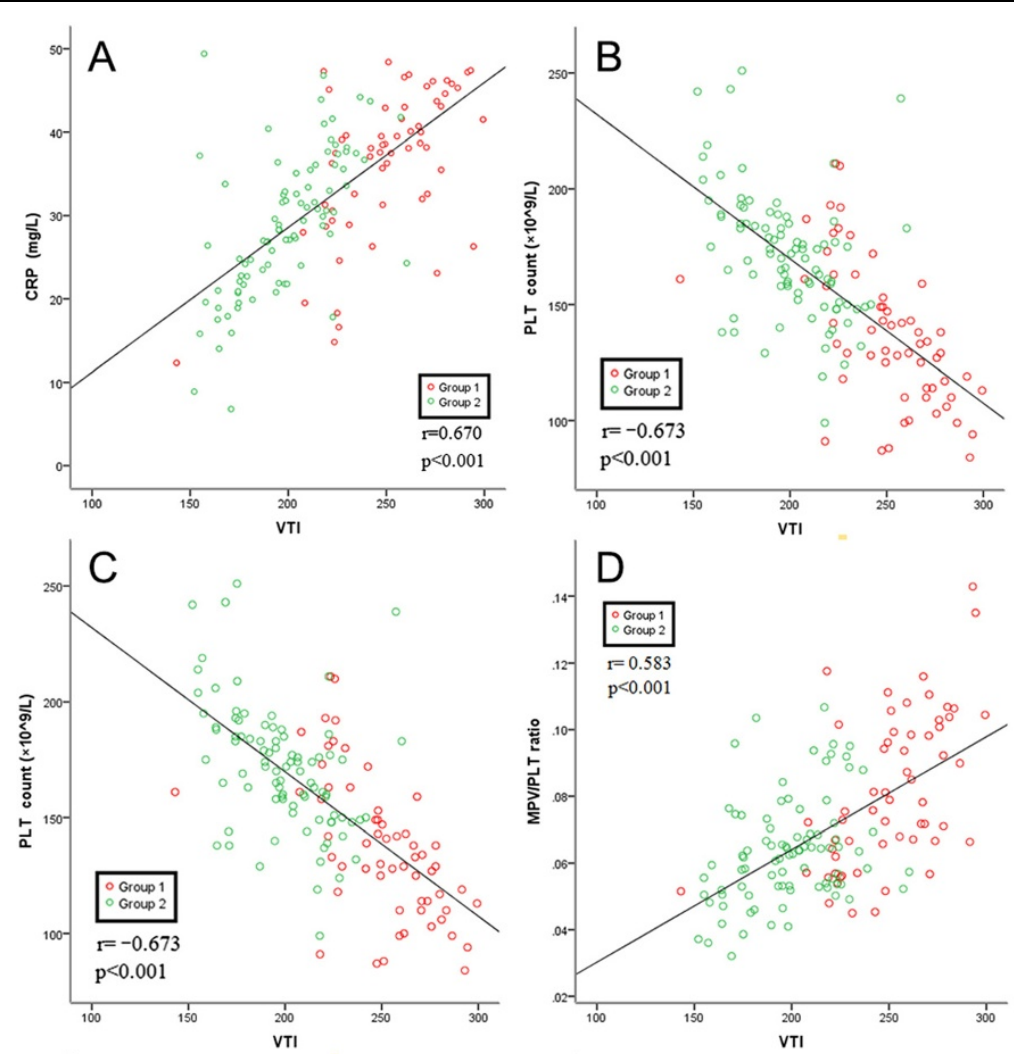

D
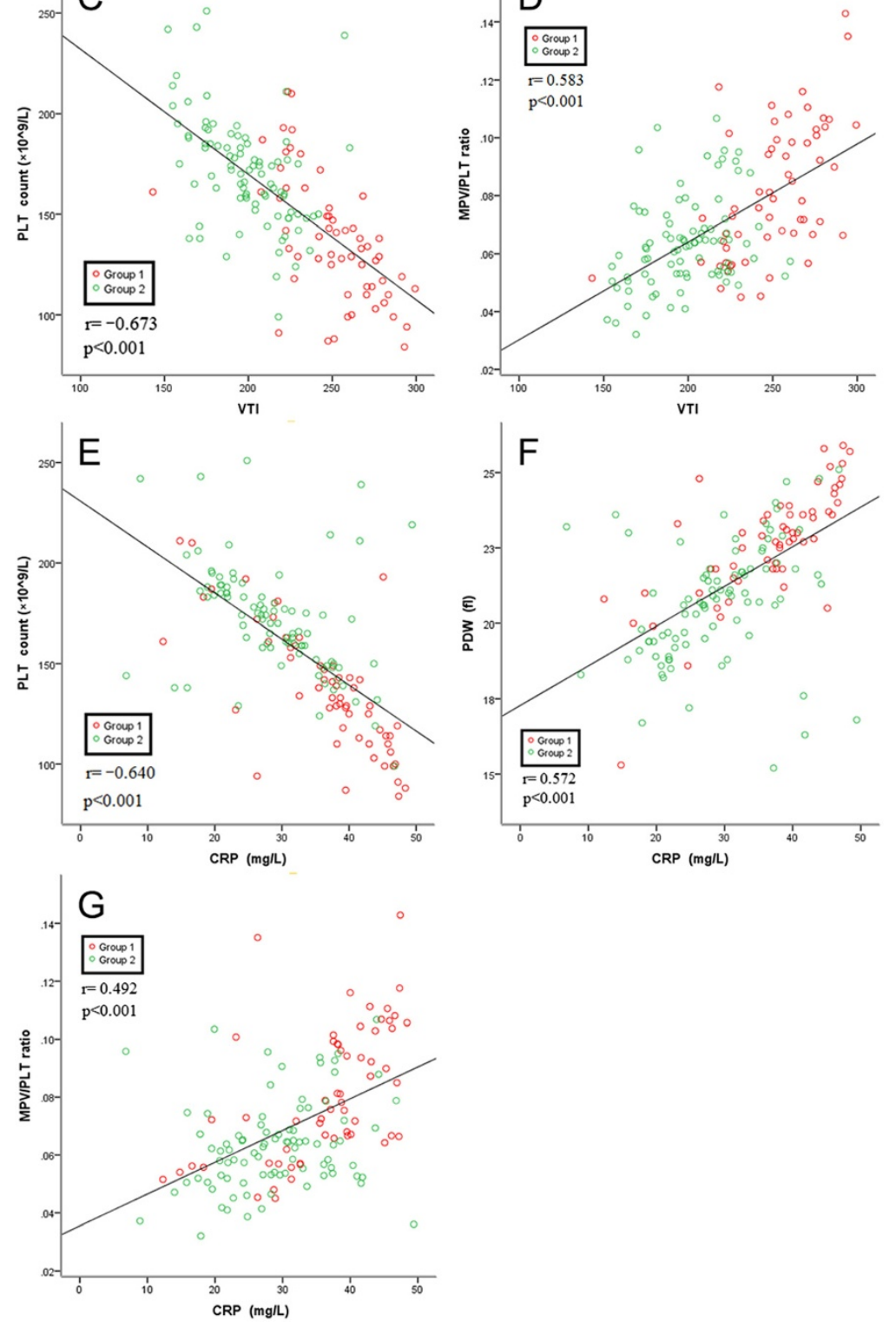

Fig. 2 a-g: Correlation of PLT indices, extent of AAD and inflammation parameters 
1 than in group $2\left(137.24 \pm 31.0 \times 10^{9} / \mathrm{L}\right.$ vs $171.43 \pm$ $\left.27.57 \times 10^{9} / \mathrm{L}, P<0.001\right)$. The MPV/PLT ratio and PDW were significantly higher in the group 1 respectively $(0.08 \pm$ 0.02 vs $0.06 \pm 0.02, P<0.001 ; 22.65 \mathrm{fl} \pm 1.87$ vs $20.69 \pm$ $1.97 \mathrm{fl}, P<0.001)$. The MPV was no difference between two groups $(P=0.718)$.

\section{Extent of AAD}

The average of FL volume of all patients was $369.42 \pm$ $57.12 \mathrm{~cm}^{3}$. FL volume was significantly larger in group 1 than in group $2\left(419.31 \pm 42.90 \mathrm{~cm}^{3}\right.$ vs $335.98 \pm$ $\left.37.81 \mathrm{~cm}^{3}, P<0.001\right)$. VTI was significantly higher in group 1 than in group $2(250.12 \pm 27.82$ vs $198.79 \pm$ 24.52, $P<0.001)$.

\section{Inflammatory parameters}

The CRP level was significantly higher in group 1 than in group $2(36.40 \pm 8.89 \mathrm{mg} / \mathrm{L}$ vs $28.97 \pm 8.48 \mathrm{mg} / \mathrm{L}, P<$ $0.001)$. WBC count, Neut $\%$ and Axillary temperature were no difference between two groups.

\section{Correlation of PLT indices, extent of AAD and inflammation parameters}

Correlation of PLT indices, extent of AAD and inflammation were presented in Fig. 2 There was a significant negative correlation between VTI and PLT count $(\mathrm{r}=-0.673$, $P<0.001)$ (Fig. 2b), CRP and PLT count $(r=-0.640, P<$ 0.001) (Fig. 2e), respectively. There was a significant positive correlation between VTI and CRP $(\mathrm{r}=0.670, P<$ 0.001) (Fig. 2a), VTI and PDW $(r=0.601, P<0.001)$ (Fig. 2c). The positive correlations were presented between VTI and MPV/PLT ratio, CRP and PDW, CRP and MPV/ PLT ratio also. Although the correlations were not as strong as above two $((\mathrm{r}=0.583, \mathrm{r}=0.572, \mathrm{r}=0.492, P<0.001$, respectivly) (Fig. 2d, f, g).

\section{Discussion}

Our study of AAD patients demonstrated greater extent of dissection in patients with a higher serum CRP ( $\mathrm{r}=$ $0.670, P<0.001)$. Patients with a greater extent of dissection also had lower PLT count $(\mathrm{r}=-0.673, P<0.001)$; and higher MPV/PLT ratio and PDW respectively $(\mathrm{r}=0.583$, $P<0.001 ; \mathrm{r}=0.601, P<0.001)$. Both CRP and PLT indices (PLT count, MPV/PLT ratio and PDW) were also significantly correlated. We believe our results provide strong evidence for the role of platelet activation in promoting inflammation in AAD. Sbarouni [7] found significant lower PLT count occurs in AAD patients also. In addition, the MPV/PLT ratio and the PDW are higher compared to chronic aortic aneurysms.

For aortic dissection, both Stanford and DeBakey classifications are qualitative, not quantitative [8]. In our study, we present a CT-based volume tear index to evaluate the extent of dissection. To best of our knowledge, there is no research report the relationship between extent of dissection and PLT activation in the world before. Diameter measurements are more widely used in most centers and clinical trials. Volumetric measurement is time-consuming and difficult to obtain in a clinic. However, evolution of postprocessing software that allows semi-automated measurements in a rather convenient and time-efficient fashion may, in the future, allows a more widespread use of this outcome parameters [6]. According to VTI, a new quantitative classification may be applied in the aortic dissection. 3D reconstruction-based volume analysis has been widely applied in many medical research fields, such as neurooncology, vascular intervention and so on $[6,9]$.

CRP, an acute phase reactant, is a sensitive and nonspecific inflammatory marker. It is produced mainly in liver by the stimulation of many cytokines, especially by IL-6. Its levels vary with inflammatory stages $[10,11]$. Plasma CRP levels are time-dependent,which increased rapidly within 4-6 h, and reached peak values at 36-50 $\mathrm{h}$, in acute inflammation, trauma or infectious diseases, and then decreased as the inflammation response was attenuated [12]. In accord with Kurabayashi's research [5], our study showed the average CRP level was 6.39 times to normal value during the first $48 \mathrm{~h}$. Our study showed there was significant correlation between inflammation and PLT activation. But the internal mechanism was not clear. $\mathrm{Wu}$ [13] reported that plasma platelet glycoprotein P- selectin and platelet cytolemma protein can adhere to circulating polynuclear neutrophils, aggravate the inflammation. And there was a significant positive correlation between VTI and CRP $(r=0.670, P<$ 0.001), Previous studies have reported that elevated plasma CRP levels were found in patients to predicting in-hospital clinical events of aortic dissection [11, 14]. So, whether VTI can be used as prognostic indicator in AAD patients, is worth further study. During the progress of $\mathrm{AD}$, exposed collagen binds to von Willbrand Factors (vWF) and glycoproteins (GP) to activate platelets. PLT activation triggers multiple pathways: (1) release of $\alpha$ - and dense granules allows for additional feedback required for platelet activation and aggregation. (2) morphological changes in platelets occur, which results in production of pseudopod-like projections and tissue factor-rich microparticles [15].

\section{Conclusions}

PLT activation and inflammation in AAD appear to be closely correlated with the extent of dissection, which possibly induced by the tear of aortic wall. Elimination of the false lumen is the goal of traditional surgery. Suppression of the PLT activation might be future targets of therapy in the prevention of systemic inflammation in AAD patients. 


\section{Competing interests}

The authors declare that they have no competing interests.

\section{Authors' contribution}

All authors read and approved the final manuscript.

\section{Acknowledgments}

This work was supported by the National Natural Science Foundation of China (81170288 and 81101060)

\section{Author details}

'Department of Emergency medicine, West China Hospital of Sichuan University, Chengdu, China. ${ }^{2}$ Department of Cardiovascular Surgery, West China Hospital of Sichuan University, Chengdu, China. ${ }^{3}$ Department of Radiology, West China Hospital of Sichuan University, Chengdu, China.

Received: 1 March 2015 Accepted: 28 October 2015

Published online: 10 November 2015

\section{References}

1. Bath PM, Butterworth RJ. Platelet size: measurement, physiology and vascular disease. Blood Coagul Fibrinolysis. 1996;7:157-61.

2. Chu SG, Becker RC, Berger PB, Bhatt DL, Eikelboom JW, Konkle B, et al. Mean platelet volume as a predictor of cardiovascular risk: a systemic review and meta-analysis. J Thromb Haemost. 2010;8:148-56.

3. Gasparyan AY, Ayvazyan L, Mikhailidis DP, Kitas GD. zMean platelet volume: a link between thrombosis and inflammation? Curr Pharm Des. 2011;17:47-58.

4. Balduini CL, Salvini M, Montani N, Noris P, Spedini P, Belletti S, et al. Activation of the hemostatic process in patients with unruptured aortic aneurysm before and in the first week after surgical repair. Haematologica. 1997:82:581-3.

5. Kurabayashi M, Okishige K, Azegami K, Ueshima D, Sugiyama K, Shimura T, et al. Reduction of the $\mathrm{PaO} 2 / \mathrm{FiO} 2$ ratio in acute aortic dissection relationship between the extent of dissection and inflammation. Circ J. 2010;10:2066-73.

6. Melissano G, Bertoglio L, Rinaldi E, Civilini E, Tshomba Y, Kahlberg A, et al. Volume changes in aortic true and false lumen after the "PETTICOAT" procedure for type B aortic dissection. J Vasc Surg. 2012;53:641-51.

7. Sbarouni E, Georgiadou P, Analitis A, Voudris V. Significant changes in platelet count, volume and size in acute aortic dissection. Int J Cardiol. 2013:4:4349-50.

8. Dake MD, Thompson M, van Sambeek M, Vermassen F, Morales JP, DEFINE Investigators. DISSECT: a new mnemonic-based approach to the categorization of aortic dissection. Eur J Vasc Endovasc Surg. 2013;2:175-90.

9. Paek SH, Kim CY, Kim YY, Park IA, Kim MS, Kim DG, et al. Correlation of clinical and biological parameters with peritumoral edema in meningioma. J Neurooncol. 2002;3:235-45.

10. Wen D, Zhou XL, Li JJ, Luo F, Zhang L, Gao LG, et al. Plasma concentrations of interleukin-6, C-reactive protein, tumor necrosis factor-a and matrix metalloproteinase-9 in aortic dissection. Clin Chim Acta. 2012;1-2:198-202.

11. Wen D, Wu HY, Jiang XJ, Zhang HM, Zhou XL, Li JJ, et al. Role of plasma C-reactive protein and white blood cell count in predicting in-hospital clinical events of acute type A aortic dissection. Chin Med J (Engl). 2011;17:2678-82.

12. Yeh ET. High-sensitivity C-reactive protein as a risk assessment tool for cardiovascular disease. Clin Cardiol. 2005;28:408-12.

13. Jinhong WU, Guogen XU, Zhijun XU, Yuansheng Xu,Qing Gu. Relationship between blood platelet activation and inflammation reaction in patients with systemic inflammatory response syndrome. Clinical Education of General Practice. 2011;9:252-4.

14. Sakakura K, Kubo N, Ako J, Wada H, Fujiwara N, Funayama H, et al. Peak C-reactive protein level predicts long-term outcomes in type B acute aortic dissection. Hypertension. 2010;2:422-9.

15. Stevic I, Chan HH, Chan AK. Carotid artery dissections: thrombosis of the false lumen. Thromb Res. 2011;4:317-24.

\section{Submit your next manuscript to BioMed Central and take full advantage of:}

- Convenient online submission

- Thorough peer review

- No space constraints or color figure charges

- Immediate publication on acceptance

- Inclusion in PubMed, CAS, Scopus and Google Scholar

- Research which is freely available for redistribution

Submit your manuscript at www.biomedcentral.com/submit 